\title{
A LIDERANÇA DA ENFERMAGEM NO CUIDADO À SAÚDE: ORIENTAÇÕES ESTRATÉGICAS DA OMS PARA OS SERVIÇOS DE ENFERMAGEM E OBSTETRÍCIA
}

Isabel Amélia Costa Mendes ${ }^{1}$

Maria Helena Palucci Marziale ${ }^{2}$

No final do século XXI, observa-se um movimento de fortalecimento da Enfermagem, refletido em diversas resoluções da Assembléia da Organização Mundial da Saúde, que reconhecem a importância e o caráter estratégico das ações de enfermagem dentre as profissões de saúde. A formação de uma Rede Global de Centros Colaboradores vinculada a OMS formaliza esta mudança e consolida um estreito vínculo dos enfermeiros com as diretrizes da Organização.

Este processo resultou no estabelecimento pela OMS de algumas orientações estratégicas para as ações de enfermagem e obstetrícia, com o intuito de facilitar a liderança das enfermeiras e parteiras no cuidado e promoção à saúde e, conseqüentemente, buscar formas inovadoras que permitam uma gestão eficaz dos serviços de saúde.

Neste sentido, ressalta-se o conceito de liderança de impacto fundamentado no pensamento de que "a liderança não é um cargo, mas uma maneira de pensar e se comportar que influencia outras pessoas"(1). Os enfermeiros devem, portanto, em sua prática profissional e acadêmica, buscar exercer uma liderança de impacto, dando início e sendo responsáveis por mudanças no cuidado à saúde.

As Orientações Estratégicas ${ }^{(2)}$ definidas pela OMS em 2002 com término previsto para 2008 oficializam este relevante papel atribuído aos enfermeiros, enfocando as seguintes áreas:

1. Planejamento e Comprometimento político para com o desenvolvimento nacional através da prestação de serviços de enfermagem e obstetrícia.

2. Administração dos serviços de enfermagem e obstetrícia com o estabelecimento de políticas de emprego para as enfermeiras e parteiras que considerem as diferenças de gênero e a necessidade de ambientes e condições adequadas de trabalho.

3. Melhoramento da prática e dos sistemas de saúde, integrando os enfermeiros no processo de tomada de decisão em todos os níveis.

4. Educação continuada dos membros da equipe de enfermagem para que adquiram as competências necessárias para lidar com os futuros desafios de sua prática.

5. Apoio aos serviços de enfermagem e obstetrícia, incluindo governo, sociedade civil e outras profissões da saúde.

Para implementação destas orientações, a OMS e outras organizações internacionais membros do sistema ONU estão dispostas a envidar esforços no sentido de garantir o reconhecimento dos serviços de enfermagem e obstetrícia como primordiais à melhora do cuidado à saúde em geral, adaptando estas diretrizes às características e necessidades de desenvolvimento específicas dos diferentes países.

A ação conjunta de governos e da sociedade é, portanto, fundamental para a implementação de ações direcionadas à capacitação construtiva dos profissionais de enfermagem, ao estímulo ao desenvolvimento de pesquisas

Editores da Revista Latino-Americana de Enfermagem da Escola de Enfermagem de Ribeirão Preto, da Universidade de São Paulo, Centro Colaborador da OMS para o desenvolvimento da pesquisa em enfermagem: ${ }^{1}$ Professor Titular, e-mail: iamendes@eerp.usp.br; ${ }^{2}$ Professor LivreDocente, e-mail: marziale@eerp.usp.br 
que embasem a prática e à formação de lideranças efetivas dentre os enfermeiros. A consecução destas ações e o cumprimento das diretrizes da OMS configuram-se em um grande desafio para a Enfermagem no novo milênio.

\section{REFERÊNCIAS BIBLIOGRÁFICAS}

1. Drucker P. O líder do futuro. São Paulo: Futura; 1996.

2. WHO Library Cataloguing - in Publication Data. Strategic directions for strengthening nursing and midwifery services. Geneva: WHO; 2002. 